\title{
LIFE CYCLE COST ANALYSIS ON ANTI-CORROSION COATINGS FOR STEEL BRIDGES IN JAPAN
}

\author{
Mikihito Hirohata \\ associate professor, Graduate School of Engineering, Osaka University \\ 2-1, Yamada-oka, Suita-shi, Osaka, 565-0871, Japan, e-mail: hirohata@civil.eng.osaka-u.ac.jp \\ Tomonori Nakahara \\ Japan Bridge Corporation \\ 2-7, 1, Sakaemachidori,Chuo-ku, Kobe-shi, Hyogo, 650-0023, Japan, e-mail: t-nakahara@nihon-kyoryo.co.jp \\ Károly Jármai \\ professor, University of Miskolc, Faculty of Mechanical Engineering and Informatics \\ 3515 Miskolc, Miskolc-Egyetemváros, e-mail: jarmai@uni-miskolc.hu
}

\begin{abstract}
A series of surveys on the cost and durability of anti-corrosion coatings for steel bridges used in Japan was performed. The life cycle cost of anti-corrosion coatings for steel bridges during their design service periods was examined under different corrosion environments. The combinations of heavyduty paint coating system as initial coating and the same coating system as repair coating showed the lowest cost when the short interval applied for the repair work. The metal coatings might be reasonable under severe corrosion environments due to their high durability.
\end{abstract}

Keywords: life cycle cost, anti-corrosion coating, steel bridge, paint coating, metal coating

\section{Introduction}

Infrastructures such as roads, tunnels and bridges should ensure stable and safe traffic service in the long term. When noting steel bridges that are typical infrastructures, damages and degradations inevitably occur during their service periods. The leading causes of damages and degradations of steel bridges are fatigue and corrosion (Fisher et al., 2011 and Kline, 2008). In Japan, a lot of steel bridges have been constructed near seaside (Kitada, 2006). Even though the bridges have also been built in mountain areas, they suffer from the influences of salt in anti-freezing materials applied in the winter season. Therefore, corrosion is the most crucial issue in the maintenance of steel bridges in Japan. For preventing corrosion damage to steel bridges, several types of anti-corrosion coatings are generally applied. However, these anti-corrosion coatings are naturally degraded in long-term use. Repair and renewal of anti-corrosion coatings are required in specific periods of time, and then, cost and environmental load will happen at the constructions. In other words, the application of anti-corrosion coatings should be considered by the initial cost and durability and the renewal cost and the durability of renewed coatings.

This study analyses the cost and durability of anti-corrosion coatings for steel bridges used in Japan. Based on the actual construction information, the life cycle cost analysis of the construction and repair of anti-corrosion coatings for steel bridges during their design service periods is examined. Further- 
more, a new technology for old paint removal can save construction time and reduce wastes and environmental loads (Konishi et al., 2017 and 2020).

\section{Anti-corrosion coatings for steel bridges}

\subsection{Paint coating}

Here, the anti-corrosion coatings used for steel bridges in Japan are briefly introduced from the viewpoints of material and cost.

The most general anti-corrosion coating is painted because of easy construction and reasonable cost. Table 1 shows the typical paint coating systems (A-5 and C-5) for newly constructed steel structures in Japan (JSSC, 2012). Basically, the paint coatings are applied by multi-layers. Firstly, the steel substrate surface should be prepared by blasting or grinding for cleaning and creating roughness to ensure adhesion between the steel and the primer or undercoat of paint. The protective underlay and the undercoat protect the steel substrate by their high corrosion resistance. The middle and the topcoats are painted on the undercoat. The topcoat inhibits the attack of degradation factors such as rain, salt and sunshine. The medium coat connects the top and undercoats.

The A-type paint system (A-5) is the same as the painting system (A-1) that have been used in Japan for a long term as a paint coating for general corrosion environment. It was specified about 20 years ago by replacing it with $\mathrm{Pb}$ - and $\mathrm{Cr}$-free paint. B-type paint systems had initially existed; however, it had been known that the paint included harmful materials for human health such as Pb or PCB. Therefore, the use of a B-type paint system had been stopped. The heavy-duty anti-corrosion paint coating system (C-5) has been mainly used for newly constructed steel structures or repairing existing structures. The C-5 paint system is composed of Zn-rich paint, epoxy resin and fluorocarbon resin.

Table 2 shows the typical paint coating systems (Ra-III, Rc-IV, and Rc-I) to repair existing steel structures. The characters of 'a' or ' $c$ ' in the system names correspond to the type of paint coating, such as A-type or C-type. The numbers of 'III', 'IV', and 'I' in the system names mean the degree of surface preparation. The type-I and type-III are blasting and grinding for removing the rust and damaged original paint coatings. The type-IV is just cleaning.

Table 1. Paint systems for newly constructed steel structures.

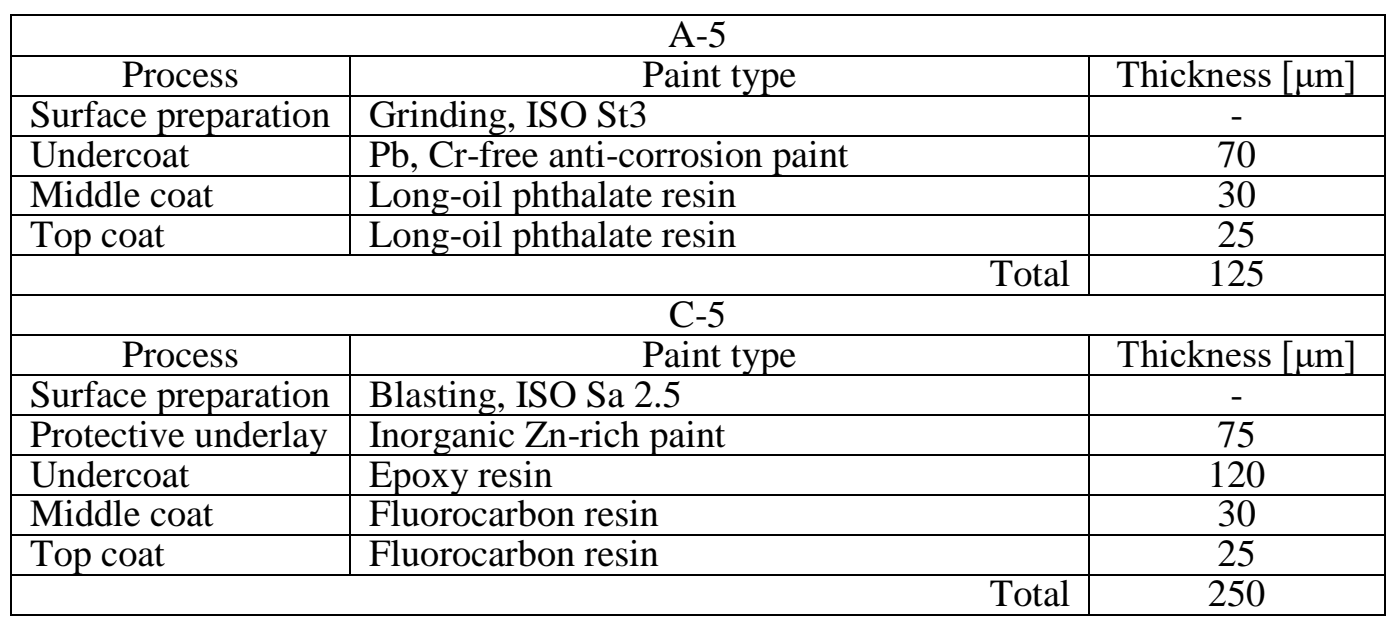


Table 2. Paint systems for repair of existing steel structures.

\begin{tabular}{|l|l|c|}
\hline \multicolumn{2}{|c|}{ Ra-III } & Weight $\left[\mathrm{g} / \mathrm{m}^{2}\right]$ \\
\hline \multicolumn{1}{|c|}{ Process } & \multicolumn{1}{|c|}{ Paint type } & - \\
\hline Surface preparation & Grinding (removing rust and deteriorated paint) & 280 \\
\hline Undercoat & Pb, Cr-free anti-corrosion paint & 120 \\
\hline Middle coat & Long-oil phthalate resin & 110 \\
\hline Top coat & Long-oil phthalate resin & 510 \\
\hline \multicolumn{2}{|c|}{ Paint type } & Weight $\left[\mathrm{g} / \mathrm{m}^{2}\right]$ \\
\hline \multicolumn{2}{|c|}{ Rc-I } & - \\
\hline \multicolumn{1}{|c|}{ Process } & \multicolumn{1}{|c|}{ Paint type } & 200 \\
\hline Surface preparation & Cleaning (removing powders and stains) & 140 \\
\hline Undercoat & Epoxy resin & 120 \\
\hline Middle coat & Fluorocarbon resin & 460 \\
\hline Top coat & Fluorocarbon resin & Weight $\left[\mathrm{g} / \mathrm{m}^{2}\right]$ \\
\hline \multicolumn{2}{|c|}{} & - \\
\hline \multicolumn{1}{|c|}{ Process } & \multicolumn{1}{|c|}{ Total } & 600 \\
\hline Surface preparation & Blasting, ISO Sa 2.5 & 480 \\
\hline Protective underlay & Organic Zn-rich paint & 240 \\
\hline Undercoat & Epoxy resin & 170 \\
\hline Middle coat & Fluorocarbon resin & 1,490 \\
\hline Top coat & Fluorocarbon resin \\
\hline \multicolumn{2}{|c|}{ Total } & \\
\hline
\end{tabular}

\subsection{Zn hot-dip galvanizing}

Zn hot-dip galvanizing provides high anti-corrosion performance of steel structures. For steel structures used under severe corrosion environments, HDZ55 specified by JIS H 8641 is applied (JSA, 2007). The weight of $\mathrm{Zn}$ must be over $550 \mathrm{~g} / \mathrm{m}^{2}$ by this specification. The life of the $\mathrm{Zn}$ galvanized layer is expected to be longer than the paint coating. Although the use of $\mathrm{Zn}$ hot-dip galvanizing is increasing gradually, the number is still less than the paint coating because of the high cost of equipment and the size limitation by the galvanizing tank.

\subsection{Thermal spraying}

Thermal spraying provides high anti-corrosion performance to steel structures as well as Zn hot-dip galvanizing by creating the metal layer on the surface of the steel. Typical materials used for thermal spraying are $\mathrm{Zn}, \mathrm{Al}, \mathrm{Zn}-\mathrm{Al}$ alloy and $\mathrm{Al}-\mathrm{Mg}$ alloy. Thermal spraying does not require a large tank such as $\mathrm{Zn}$ hot-dip galvanizing. The temperature rise by thermal spraying is lower than $\mathrm{Zn}$ hot-dip galvanizing. Furthermore, the thickness of the metal layer is possible to be controlled. However, thermal spraying is still more expensive than paint coating. Therefore, thermal spraying is basically applied to local parts in steel bridges such as girder ends or bearings where corrosion damages are prone to occur (Figure 1). 
The process of thermal spraying includes surface preparation by blasting, spraying and sealing. The sealing means that the surface of the sprayed metal layer with fine pinholes is covered by some agents.
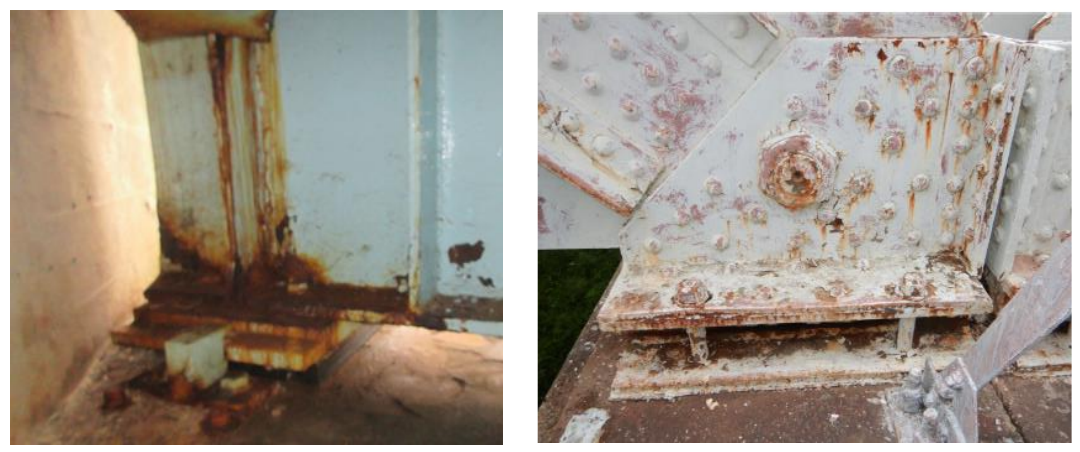

Figure 1. Local parts in steel bridges prone to corrosion.

\section{Cost and durability of anti-corrosion coatings}

\subsection{Cost of anti-corrosion coatings}

Here, costs for the anti-corrosion coatings are estimated based on an actual example of construction in Japan. For the cost estimation, the construction of a steel I-section girder bridge is assumed. The bridge size with a span of $38 \mathrm{~m}$, the height of $2.0 \mathrm{~m}$, the width of $11 \mathrm{~mm}$ and the weight of 108 tons will provide the area for coating of $1,600 \mathrm{~m}^{2}$. The site is assumed as an urban region, and the construction work is considered to be performed during the daytime without any restriction.

The estimated construction costs of anti-corrosion coatings are shown in Table 3 . These costs are based on general construction prices in June 2021 in Japan. The conversion from JPY to EUR is based on the rate in July $2021(1 \mathrm{ERU}=130.90 \mathrm{JPY})$. The normalized costs by the price of the A-5 paint coating system are also shown in the table.

Figures 2, 3 and 4 show the contents and normalized costs for each coating. The cost of management means the personnel expenses, record of construction, severance and other related expenses. The coatings for new structures are basically performed in the factory, although a part of the A-5 paint coating system is applied on site. On the other hand, the repair work for existing structures is performed on-site. Then, a scaffold for construction will be required. The costs for repair work include the rental fee and removal expenses of scaffolds as the site construction. Noting the paint coating systems (Figure 2), the rate of expenses for site construction of repair paint coatings (Ra-III, Rc-IV and Rc-I) are relatively large. Furthermore, the surface preparation of Rc-I is considerably larger because the blasting on-site, including the collection and disposal of waste, requires a high cost.

The $\mathrm{Zn}$ hot-dip galvanizing and the thermal spraying are summarized as the metal coatings for newly constructed structures (Figure 3). The costs of thermal spraying are 3 to 4 times higher than the cost of $\mathrm{Zn}$ galvanizing. Naturally, the $\mathrm{Zn}$ hot-dip galvanizing is not available for repair coating of existing structures. The cost of repair thermal spraying is exceptionally high, as shown in the vertical axis range in Figure 4. However, the thermal repair spraying is basically applied to local parts of existing structures, as mentioned above. The total cost for repair thermal spraying depends on the area in which the repair coating is required. 
Table 3. Costs of coatings for newly constructed structures.

\begin{tabular}{|c|c|c|c|c|}
\hline \multicolumn{5}{|c|}{ Coatings for newly constructed structures } \\
\hline \multirow{2}{*}{ Coating type } & \multirow{2}{*}{ Specification } & \multicolumn{3}{|c|}{ Cost } \\
\hline & & $\mathrm{JPY} / \mathrm{m}^{2}$ & $\mathrm{EUR} / \mathrm{m}^{2}$ & Normalized by $*$ \\
\hline \multirow[b]{2}{*}{ Paint coating } & $\mathrm{A}-5^{*}, 125 \mu \mathrm{m}$ & 5,829 & 45 & 1.00 \\
\hline & $\mathrm{C}-5,250 \mu \mathrm{m}$ & 8,996 & 69 & 1.54 \\
\hline Zn galvanizes & HDZ55, $77 \mu \mathrm{m}$ & 7,363 & 56 & 1.26 \\
\hline \multirow{4}{*}{ Thermal spraying } & $\mathrm{Zn}, 100 \mu \mathrm{m}$ & 22,211 & 170 & 3.81 \\
\hline & $\mathrm{Zn}-\mathrm{Al}, 100 \mu \mathrm{m}$ & 22,211 & 170 & 3.81 \\
\hline & $\mathrm{An}, 150 \mu \mathrm{m}$ & 25,623 & 196 & 4.40 \\
\hline & $\mathrm{Al}-\mathrm{Mg}, 150 \mu \mathrm{m}$ & 26,937 & 206 & 4.62 \\
\hline \multicolumn{5}{|c|}{ Repair coatings for existing structures } \\
\hline \multirow[b]{2}{*}{ Coating type } & \multirow{2}{*}{ Specification } & \multicolumn{3}{|c|}{ Cost } \\
\hline & & $\mathrm{JPY} / \mathrm{m}^{2}$ & $\mathrm{EUR} / \mathrm{m}^{2}$ & Normalized by * \\
\hline \multirow{3}{*}{ Paint coating } & Ra-III, $125 \mu \mathrm{m}$ & 11,010 & 84 & 1.89 \\
\hline & Rc-IV, $(175 \mu \mathrm{m})$ & 9,846 & 75 & 1.69 \\
\hline & 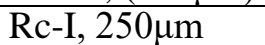 & 35,135 & 268 & 6.03 \\
\hline \multirow{4}{*}{ Thermal spraying } & $\mathrm{Zn}, 100 \mu \mathrm{m}$ & 131,252 & 1,003 & 22.52 \\
\hline & $\mathrm{Zn}-\mathrm{Al}, 100 \mu \mathrm{m}$ & 131,252 & 1,003 & 22.52 \\
\hline & $\mathrm{Al}, 150 \mu \mathrm{m}$ & 147,143 & 1,124 & 25.24 \\
\hline & $\mathrm{Al}-\mathrm{Mg}, 150 \mu \mathrm{m}$ & 155,830 & 1,190 & 26.73 \\
\hline
\end{tabular}

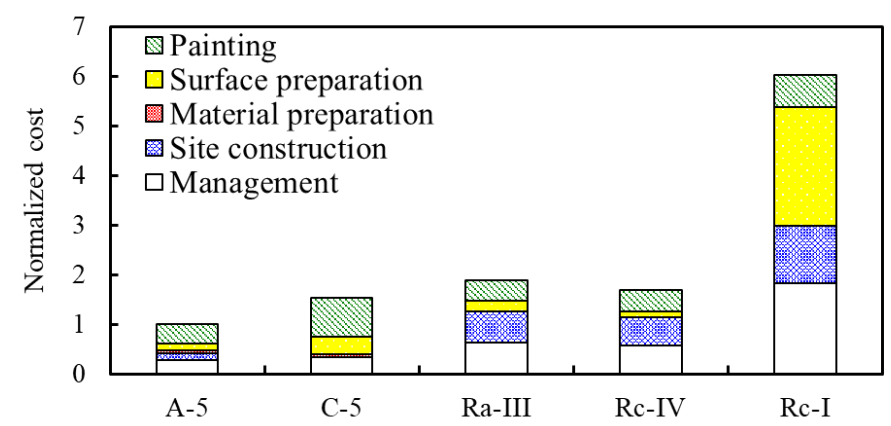

Figure 2. Contents and normalized costs for paint coatings.

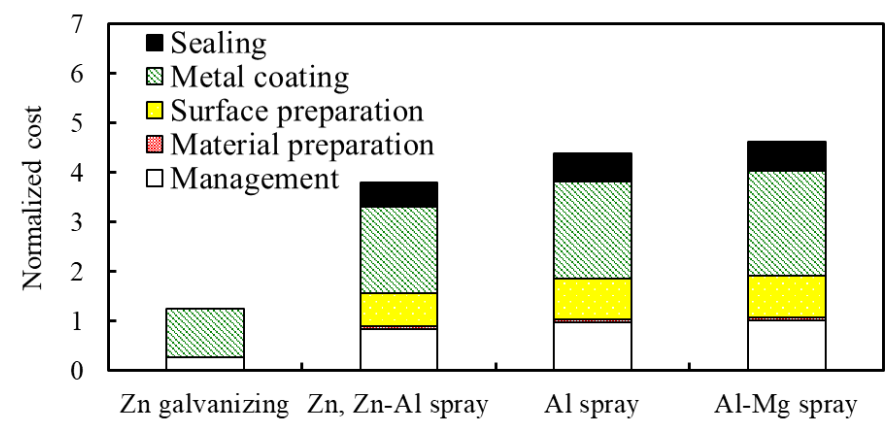

Figure 3. Contents and normalized costs for metal coatings. 


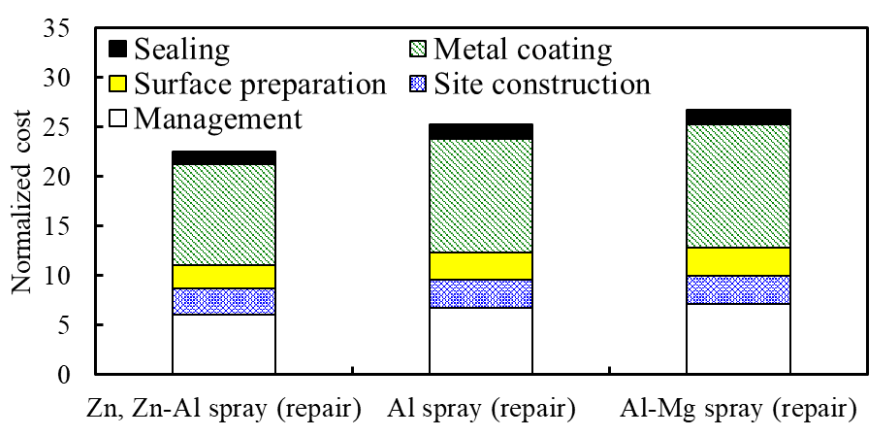

Figure 4. Contents and normalized costs for repair thermal repair spraying.

\subsection{The durability of anti-corrosion coatings}

Table 4 shows the design service periods of each coating. The design service periods depend on the corrosion environments. The category of 'Low' corresponds to atmospheres with a low level of pollution, such as rural areas. 'Medium' means urban areas with moderate pollution. 'High' means industrial areas and coastal areas with moderate salinity. 'Very high' corresponds to coastal areas with high salinity (Tanabe, 2020).

The A-5 and Ra-III paint coating systems are not available for High and Very high corrosion environments. The service period of them is not long even under the Low and Medium corrosion environments. The C-5, Rc-IV and Rc-I paint coating systems are available under the High and the Very high corrosion environments. The service periods of them are 3 to 4 times longer than that of the A-5 paint coating system. The difference of service periods of Rc-IV and Rc-I is caused by the degree of surface preparation. The surface preparation of Rc-IV is grinding, while that of Rc-I is blasting.

The metal coatings have the most extended service periods than the paint coatings. The service periods of metal coatings exceed 100 years under the Low corrosion environment. However, the Zn galvanizing and the thermal spraying by $\mathrm{Zn}$ have shorter service periods than the C-5 paint coating system under the High and Very high corrosion environments. Although the thermal spraying by $\mathrm{Al}$ and Al-Mg shows very long service periods, the accurate experimental data is few. Therefore, the service periods of thermal spraying should be continuously investigated (Kuroda et al., 2006).

Table 4. Design service periods of each coating (years).

\begin{tabular}{|c|c|c|c|c|c|}
\hline \multirow{2}{*}{$\begin{array}{l}\text { Corrosion en- } \\
\text { vironments }\end{array}$} & \multicolumn{2}{|c|}{ Painting for new structures } & \multicolumn{3}{|c|}{ Repair painting for existing structures } \\
\hline & A-5 & $\mathrm{C}-5$ & Ra-III & Rc-IV & Rc-I \\
\hline Low & 15 & 60 & 15 & 40 & 60 \\
\hline Medium & 10 & 45 & 10 & 30 & 45 \\
\hline High & - & 30 & & 20 & 30 \\
\hline Very high & - & 20 & & 10 & 20 \\
\hline Corrosion en- & Zn galvanizing & \multicolumn{4}{|c|}{ Thermal spraying } \\
\hline vironments & HDZ55 & $\mathrm{Zn}$ & $\mathrm{Zn}-\mathrm{Al}$ & $\mathrm{Al}$ & Al-Mg \\
\hline Low & 100 & 100 & 100 & 120 & 150 \\
\hline Medium & 60 & 70 & 70 & 100 & 150 \\
\hline High & 25 & 30 & 60 & 80 & 120 \\
\hline Very high & 10 & 15 & 30 & 60 & 100 \\
\hline
\end{tabular}




\section{Life cycle cost of anti-corrosion coatings}

\subsection{Scenarios of analysis}

Here, the analysis of the life cycle cost of anti-corrosion coatings is based on the costs and design service periods for new construction and repair construction mentioned in the above chapter. For the analysis, combinations of the initial coating and the repair coating, i.e., scenarios, should be decided.

Table 5 shows the scenarios of the life cycle cost analysis in this study. The scenarios from No. 1 to No. 4 are the combinations of initial and repair paint coatings. The A-5 paint coating system is susceptible to deterioration. The Rc-IV paint coating system is not suitable for repairing the A-5 paint coating system because it is basically intended for repairing C-type paint coating system in which the protective underlay and undercoat have not deteriorated. The thermal spraying might not repair the initial paint coatings because the degradation of paint coatings might spread widely. It is not reasonable that the local repair by thermal spraying is applied to the wide area.

The scenario of No. 5 is the combination of the Zn galvanizing as initial coating and the Rc-I paint coating system as repair coating. This is because the $\mathrm{Zn}$ galvanizing cannot be repaired by the same $\mathrm{Zn}$ galvanizing on site. Furthermore, blasting will be required to repair the $\mathrm{Zn}$ galvanizing so that the Rc-I paint coating system should be selected as the repair coating.

The scenarios from No. 6 to 9 are the cases of thermal spraying. Basically, the initial coatings of thermal spraying might be repaired by the same thermal spraying. The scenarios from No. 10 to 13 are the combinations of the thermal spraying as initial coating and the RC-I paint coating system as repair coating. As well as the $\mathrm{Zn}$ galvanizing, the metal coatings by thermal spraying should be repaired by the Rc-I paint coating systems with blasting as surface preparation.

These scenarios are examined under the different corrosive environments such as the Low, the Medium, the High and Very high.

Table 5. Scenarios of life cycle cost analysis.

\begin{tabular}{|c|l|l|c|l|l|}
\hline No. & \multicolumn{1}{|c|}{ Initial coating } & \multicolumn{1}{|c|}{ Repair coating } & No. & \multicolumn{1}{|c|}{ Initial coating } & \multicolumn{1}{|c|}{ Repair coating } \\
\hline 1 & Paint: A-5 & Paint: Ra-III & 8 & Al spraying & Al spraying \\
\hline 2 & Paint: A-5 & Paint: Rc-I & 9 & Al-Mg spraying & Al-Mg spraying \\
\hline 3 & Paint: C-5 & Paint: Rc-IV & 10 & Zn spraying & Paint: Rc-I \\
\hline 4 & Paint: C-5 & Paint: Rc-I & 11 & Zn-Al spraying & Paint: Rc-I \\
\hline 5 & Zn galvanizing & Paint: Rc-I & 12 & Al spraying & Paint: Rc-I \\
\hline 6 & Zn spraying & Zn spraying & 13 & Al-Mg spraying & Paint: Rc-I \\
\hline 7 & Zn-Al spraying & Zn-Al spraying & \multicolumn{3}{|l}{} \\
\hline
\end{tabular}

\subsection{Analysis results of life cycle cost}

\subsubsection{Low corrosion environment}

The life cycle costs of anti-corrosion coatings are analyzed with the period of 100 years, which is the basic design service period of bridges in Japan (JRA, 2017). Figure 5 shows the analysis results of life cycle costs under the Low corrosion environment. In the case of paint coatings, the combination of C5 and Rc-IV (No. 4) shows the lowest cost. However, The Zn galvanizing (No. 5) shows the lowest cost under the Low corrosion environment because it does not require repair during the term of 100 years (Figure 5 (a)). The thermal sprayings as initial coatings do not require repair during the term of 100 years as well as the $\mathrm{Zn}$ galvanizing. Furthermore, the initial costs of the $\mathrm{Zn}$ spraying and the $\mathrm{Zn}$ Al spraying are the same. Therefore, the scenarios of No. 6, 7, 10 and 11 show the same trace of life 
cycle cost. In the same way, the scenarios of No. 8 and 12, the scenarios of No. 9 and 13 show the same trace of life cycle cost, respectively (Figure 5 (b)). However, their initial costs are higher than the life cycle costs of paint coatings or $\mathrm{Zn}$ galvanizing.

\subsubsection{Medium corrosion environment}

Figure 6 shows the analysis results of life cycle costs under the Medium corrosion environment. In the case of paint coatings, the combination of the C-5 and Rc-IV (No. 4) shows the lowest cost as well as the Low corrosion environment. It became slower than the cost of Zn galvanizing (No. 5) because the Zn galvanizing requires repair during the term of 100 years under this corrosion environment (Figure 6 (a)). The thermal sprayings of $\mathrm{Zn}$ or $\mathrm{Zn}-\mathrm{Al}$ (No. 6, 7, 10 and 11) and the thermal sprayings of $\mathrm{Al}$ (No. 8 and 12) require the repair as well as $\mathrm{Zn}$ galvanizing. The thermal spraying of $\mathrm{Al}-\mathrm{Mg}$ (No. 9 and 13) as an initial coating does not require repair (Figure 6 (b)). Of course, the damaged thermal sprayings of $\mathrm{Zn}, \mathrm{Zn}-\mathrm{Al}$ and $\mathrm{Al}$ should be repaired by the paint coating of Rc-I rather than the same thermal sprayings. However, the thermal spraying of Al-Mg without repair shows the lowest cost among the thermal sprayings under the Medium corrosion environment.

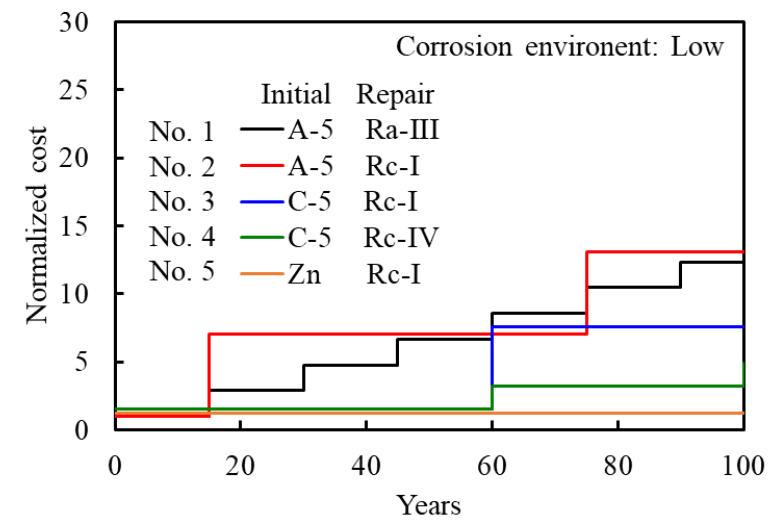

(a) Paint coatings and $\mathrm{Zn}$ galvanizing

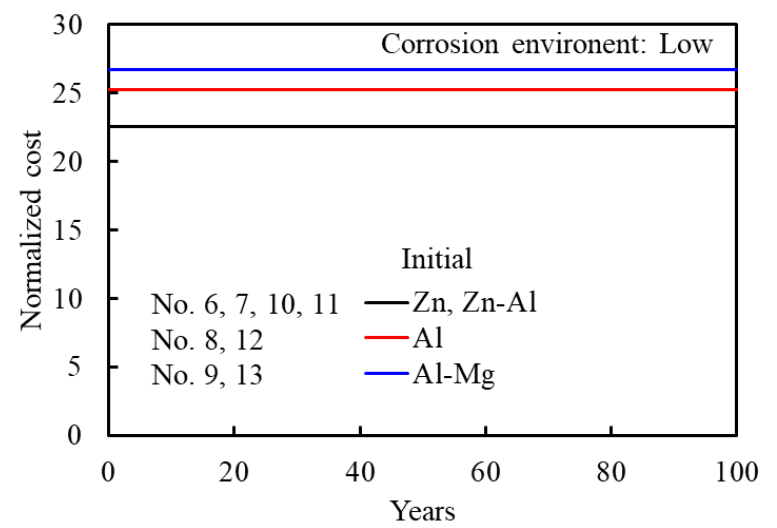

(b) Thermal spraying

Figure 5. Life cycle costs of coatings under a Low corrosion environment.

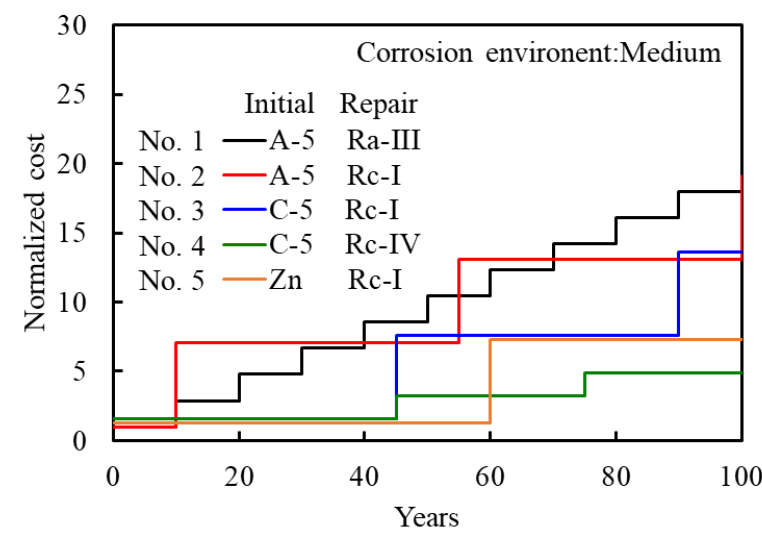

(a) Paint coatings and $\mathrm{Zn}$ galvanizing

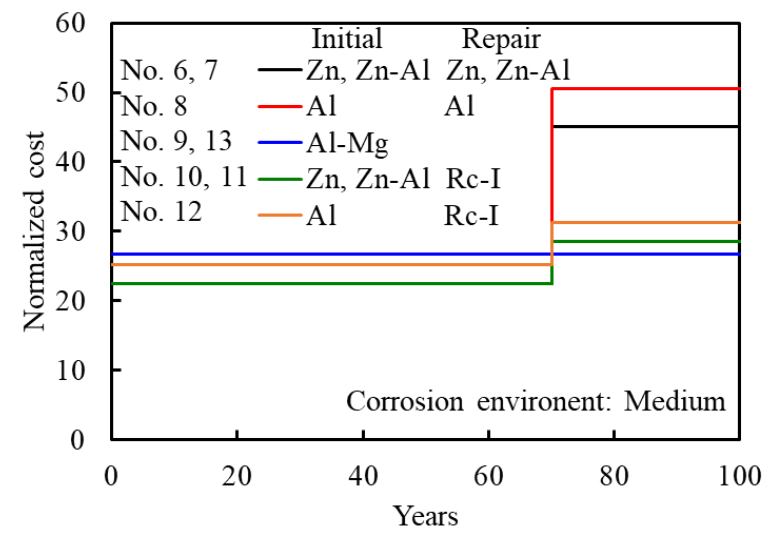

(b) Thermal spraying

Figure 6. Life cycle costs of coatings under a Medium corrosion environment. 


\subsubsection{High corrosion environment}

Figure 7 shows the analysis results of life cycle costs under the High corrosion environment. The A-5 paint coating system is not available in this corrosion environment; therefore, the scenarios of No. 1 and No. 2 are not considered. The combination of the C-5 and Rc-IV (No. 4) shows the lowest cost as well as the Medium corrosion environments (Figure 7 (a)). The thermal sprayings of $\mathrm{Zn}$ (No. 6), Zn$\mathrm{Al}$ (No. 7) and $\mathrm{Al}$ (No. 8) Require the repair during the term of 100 years under the High corrosion environment. Therefore, the higher costs for repair are estimated in these cases (Figure 7 (b)). The thermal spraying of Al-Mg (No. 9 and 13) as initial coatings does not require repair. Although the repair of damaged thermal sprayings of $\mathrm{Zn}, \mathrm{Zn}$-Al by the paint coating of RC-I provides lower costs than the repair by thermal sprayings, the thermal spraying of $\mathrm{Al}-\mathrm{Mg}$ without repair shows the lowest cost among the thermal sprayings under the High corrosion environment (Figure 7 (c)).

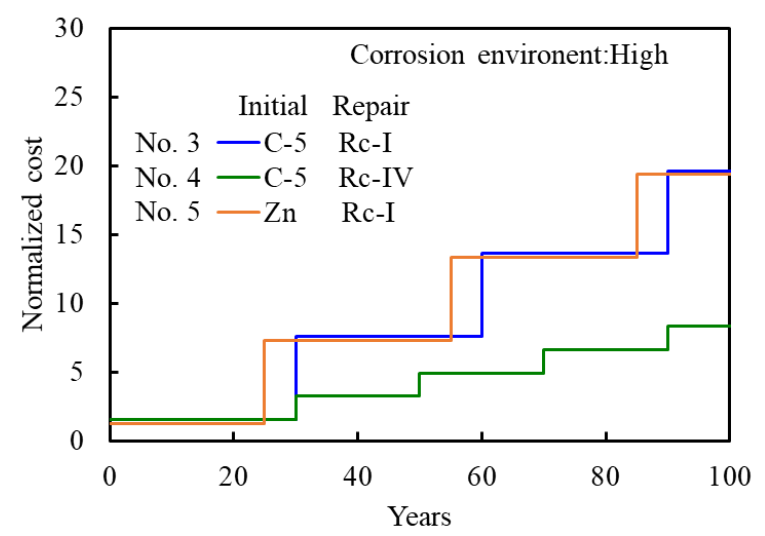

(a) Paint coatings and Zn galvanizing

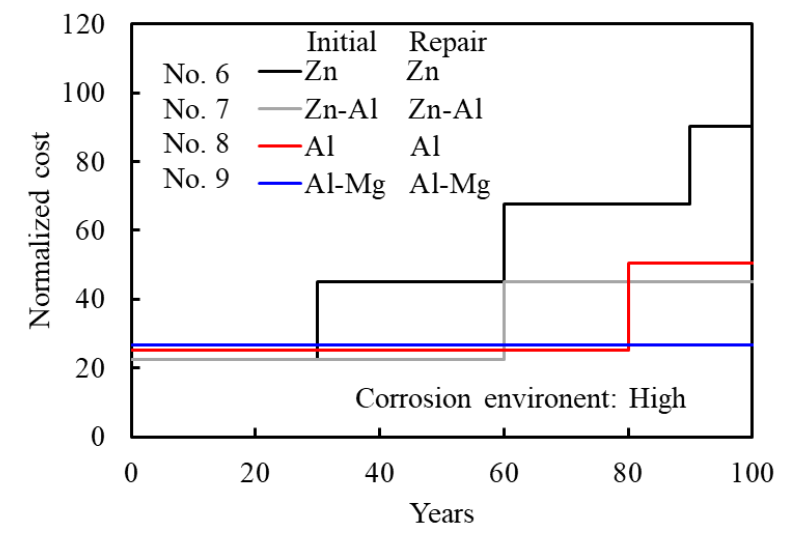

(b) Thermal spraying repaired by thermal spraying

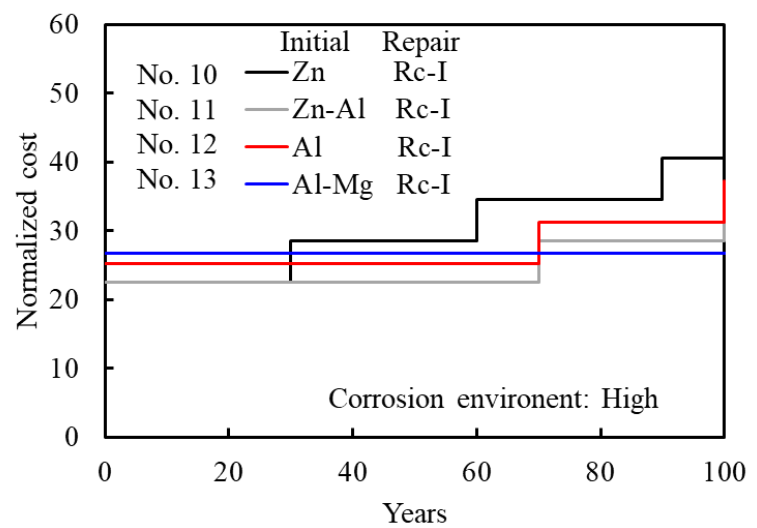

(c) Thermal spraying repaired by painting

Figure 7. Life cycle costs of coatings under a High corrosion environment.

\subsubsection{Very high corrosion environment}

Figure 8 shows the analysis results of life cycle costs under the Very high corrosion environment. The tendencies of analysis results are basically similar to those under the High corrosion environment. The combination of the C-5 and Rc-IV (No. 4) still shows the lowest cost as well as the other corrosion environments (Figure 8 (a)). In the cases of Zn galvanizing (No. 5) and thermal sprayings by Zn (No. 
6) and $\mathrm{Zn}-\mathrm{Al}$ (No. 7), the costs become higher than the cases under the High corrosion environment due to the corrosion susceptibility of $\mathrm{Zn}$ (Figure 8(b)). The differences between them and the thermal sprayings by $\mathrm{Al}$ (No. 8) or Al-Mg (No.9) become larger. Only the thermal spraying of Al-Mg (No. 9 and 13) as initial coatings does not require the repair. The thermal spraying of Al-Mg is possibly reasonable under the Very high corrosion environment (Figure 8 (c)).

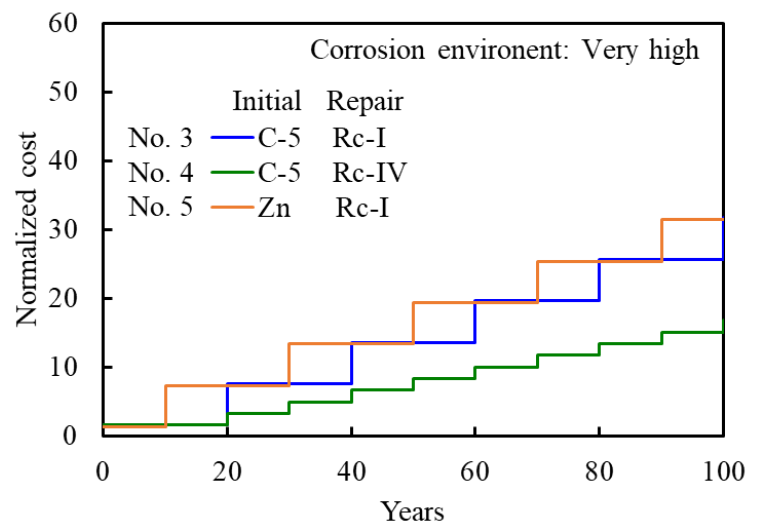

(a) Paint coatings and $\mathrm{Zn}$ galvanizing

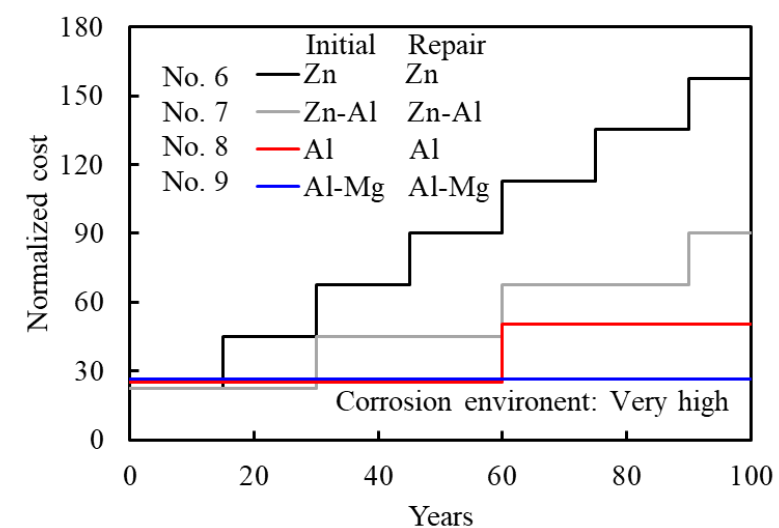

(b) Thermal spraying repaired by thermal spraying

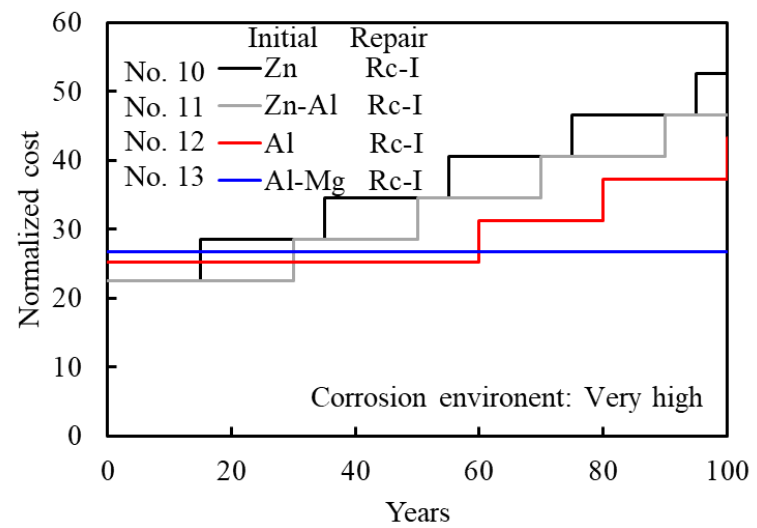

(c) Thermal spraying repaired by painting

Figure 8. Life cycle costs of coatings under a Very high corrosion environment.

\section{IH paint-coating removal technology}

As shown in the contents of costs for paint coatings (Figure 2), the ratio of surface preparation in the repair paint coating system by Rc-I is considerably high. This is because the surface preparation includes the removal of rust and deteriorated original paint coatings. The rust and paint coatings should be removed properly; that is, the noise and scatter by blasting or grinding of power tools must be suppressed near the residential area. The safety and health conditions of workers should have cared. It is especially important for treating the paint coatings with harmful materials such as Pb or PCB. Although the use of a paint-coating removal agent is one of the countermeasures to these difficulties, 
there is a risk of fire accidents in the use of an organic paint-coating removal agent (Osawa, 2021). These difficulties eventually increase the construction costs of renewal coating.

A newly developed paint coating removal technology using induction heating (IH) has been noted as an alternative method (Konishi et al., 2017 and 2020). Figure 9 shows the appearance of paintcoating removal by IH device and the principle of this technology. A high-frequency current is applied to a coil in the device. When the device is put close to the target steel member, eddy current is induced in the steel. The resistance heat is generated in the steel due to the eddy current. The temperature of the steel surface, that is, the boundary to the paint coating immediately (in few seconds) increase up to 150 to 200 degrees Celsius. This temperature rise reduces the adhesion of paint coating to the steel. It makes it easy to peal off the paint coating using a simple hand tool such as a scraper. The IH paintcoating removal reduces noise and waste generation than other methods using power tools or blasting. Also, it reduces the risk of fire because no flammable gases are generated. The removed paint coatings can be easily managed as sheet-type waste without any other materials such as grinding for blasting or paint-coating removal agents.

The IH paint-coating removal has been applied to a steel bridge in Japan (Nakahara et al., 2020). As an example, the application area of $\mathrm{IH}$ paint-coating removal was $11,100 \mathrm{~m}^{2}$. The amount of waste in this part was 2.0 tons per $1,000 \mathrm{~m}^{2}$ if the coating film thickness was $1 \mathrm{~mm}$. It meant that about 22 tons of waste were generated. If the paint-coating removal agent is used for this part, it might be required that the agent is applied 4 times. The amount of agent used is estimated as 2.0 tons per $1,000 \mathrm{~m}^{2}$. The waste by the paint-coating removal agent includes the removed coatings ( 22 tons) and the used agent (22 tons). That is, the amount of waste might be 44 tons per $1,000 \mathrm{~m}^{2}$. Even though the rough estimation, the IH paint-coating removal possibly reduce the waste by $50 \%$ compared to the use of paint-coating removal agent. The moving speed of the IH device is from $2.5 \mathrm{~m} / \mathrm{min}$ to $3.0 \mathrm{~m} / \mathrm{min}$. The width of the coil head is around $200 \mathrm{~mm}$. That is, the area of $0.5 \mathrm{~m}^{2}$ to $0.6 \mathrm{~m}^{2}$ can be heated per $1 \mathrm{mi}-$ nute. Even though the preparation time and the scraping time after the heating should be considered, the IH paint-coating removal might achieve quick works $\left(6.0 \mathrm{~m}^{2} / \mathrm{h}\right.$ to $\left.10,0 \mathrm{~m}^{2} / \mathrm{h}\right)$ compared to the other methods. Several potential merits are expected to the IH paint-coating removal; therefore, the authors performed continuous research related to this technique.

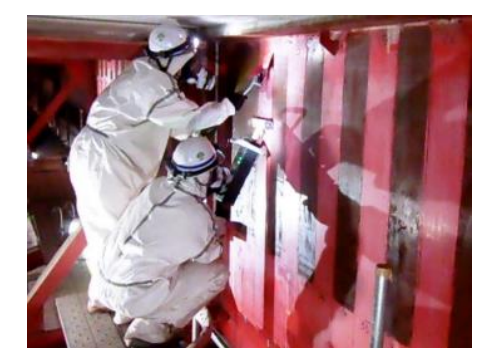

(a) Appearance of paint-coating removal

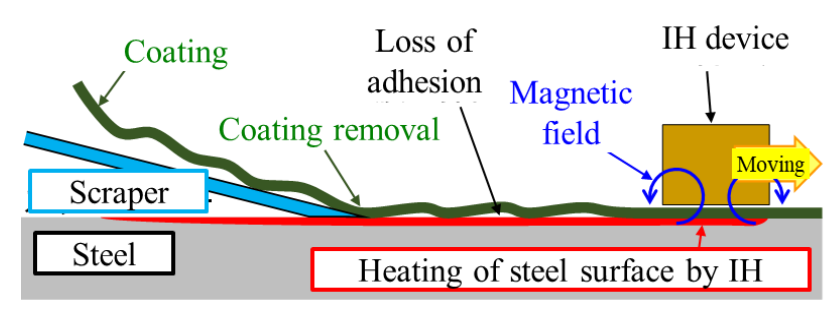

(b) Principle of IH paint-coating removal

Figure 9. IH paint-coating removal.

\section{Summary}

A series of surveys on the cost and durability of anti-corrosion coatings for steel bridges used in Japan was performed. The life cycle cost analysis on anti-corrosion coatings for steel bridges during their 
design service periods was examined based on the actual construction information. The main results obtained in this study are as follows.

(1) The Zn hot-dip galvanizing shows the lower cost than the paint coating systems under the Low corrosion environment because it does not require the repair during the analysis term of 100 years in this study.

(2) Combining the C-5 paint coating system as initial coating and the Rc-IV paint coating system as repair coating shows the lowest cost under the Medium and High corrosion environments. It is reasonable that the heavy-duty anti-corrosion painting is repaired by the relatively short intervals before severe degradation occurs.

(3) The durability of thermal spray coatings is high, although their initial and repair costs are also high. The combination of the thermal spray coatings as initial coating and the Rc-I paint coating system as repair coating is reasonable under the High and Very high corrosion environments.

\section{References}

[1] Fisher, J. W., Roy, S. (2011). Fatigue of steel bridge infrastructure. Structure and Infrastructure Engineering, Maintenance, Management, Life-Cycle Design and Performance, 7, 457-475. https://doi.org/10.1080/15732479.2010.493304

[2] Kline, E. S. (2008). Steel Bridges: Corrosion Protection for 100 Years. Journal of Protective Coatings \& Linings, 20-31.

[3] Kitada, T. (2006). Considerations on recent trends in, and future prospects of, steel bridge construction in Japan. Journal of Constructional Steel Research, 62(11), 1192-1198. https://doi.org/10.1016/j.jcsr.2006.06.016

[4] Konishi, H., Suzuki, N., Tanaka, M., Samejima, C., Nishitani, T., Hirohata, M. (2017). Application of induction heating for removal coating in Kyoda Steel Bridge. Bridge and Foundation Engineering, 7, 14-20 (in Japanese).

[5] Konishi, H., Ihaya, T., Fukushima, N., Matsui, T., Hayashi, M., Hirohata, M. (2020). Field test of coating removal by induction heating in Ichikawa Bridge. Bridge and Foundation Engineering, 6, 18-23 (in Japanese).

[6] Japanese Society of Steel Constrution. (2012). Heavy Duty Coating. Gihodobooks (in Japanese).

[7] Japanese Standard Association. (2007). Hot dip galvanized coatings. JIS H 8641 (in Japanese).

[8] Tanabe, H. (2020). Trend of ISO organization and activity of paint industry for ISO. Journal of the Surface Finishing Society of Japan, 71(8), 503-511 (in Japanese). https://doi.org/10.4139/sfj.71.503

[9] Kuroda, S., Kawakita, J., Sturgeon, A. (2006). Thermal spray coatings for corrosion prevention - current status and future perspective -. Zairyo-to-Kankyo, 55(2), 2-12 (in Japanese). https://doi.org/10.3323/jcorr.55.2

[10] Japan Road Association. (2017). Specifications for Highway bridges, Part 2 Steel Bridges and Steel Members. Maruzen Junkudo Bookstores (in Japanese).

[11] Osawa, T. (2021). Problems of repainting with heavy-duty coating and countermeasures. Journal of the Japan Society of Colour Material, 94(3), 85-92 (in Japanese). https://doi.org/10.4011/shikizai.94.85

[12] Nakahara, T., Hirohata, M., Kirihata, M. (2020). Influence of heating for IH coating removal on deformation of diagonal members in A steel deck truss bridge. Proceedings of Constructional Steel, 28, 761-770 (in Japanese). 